BULLETIN Bulletin hispanique

HISPANIQUE Université Michel de Montaigne Bordeaux

118-2 | 2016

Varia

\title{
Francisco del Villar, Fragmentos del Compendio
}

poético

Editado por Jesús Ponce Cárdenas, Paris-Sorbonne, 2016

Luis Castellví Laukamp

\section{CpenEdition}

\section{Journals}

Edición electrónica

URL: http://journals.openedition.org/bulletinhispanique/4680

DOI: 10.4000/bulletinhispanique.4680

ISSN: 1775-3821

\section{Editor}

Presses universitaires de Bordeaux

\section{Edición impresa}

Fecha de publicación: 15 diciembre 2016

Paginación: 733-735

ISBN: 979-10-300-0125-9

ISSN: 0007-4640

\section{Referencia electrónica}

Luis Castellví Laukamp, «Francisco del Villar, Fragmentos del Compendio poético », Bulletin hispanique

[En línea], 118-2 | 2016, Publicado el 15 diciembre 2016, consultado el 23 septiembre 2020. URL :

http://journals.openedition.org/bulletinhispanique/4680; DOI : https://doi.org/10.4000/

bulletinhispanique.4680

Este documento fue generado automáticamente el 23 septiembre 2020

Tous droits réservés 


\section{Francisco del Villar, Fragmentos del Compendio poético}

Editado por Jesús Ponce Cárdenas, Paris-Sorbonne, 2016

Luis Castellví Laukamp

\section{REFERENCIA}

Francisco del Villar, Fragmentos del Compendio poético, editado por Jesús Ponce Cárdenas, 2016 (LABEX OBVIL) http://obvil.paris-sorbonne.fr/corpus/gongora/1636_compendiopoetico/

1 La presente edición de los Fragmentos del Compendio poético forma parte del proyecto de edición digital y estudio de la polémica gongorina («Proyecto Góngora») dirigido por Mercedes Blanco en el marco del Labex Obvil (Observatoire de la vie littéraire, Sorbonne Université). A diferencia de las aportaciones de Jáuregui, Lope, y Francisco de Córdoba, manejadas asiduamente por generaciones de estudiosos de Góngora, esta contribución a la controversia es menos frecuentada. Por ello, la publicación del Compendio es una excelente noticia.

2 El texto va precedido de un estudio que enmarca la obra en la biografía del autor y en su contexto histórico y literario. Siguiendo el esquema impuesto por el proyecto, nueve apartados dan cuenta del título escogido, la vida de Francisco del Villar (c. 1565-1639), la datación del Compendio (c. 1635-1636), la estructura de los dos capítulos conservados, sus fuentes, los principales asuntos tratados, y el establecimiento del texto. La bibliografía es nutrida e incluye tres obras más de Villar, todavía no estudiadas. Por otra parte, los hipervínculos permiten acceder fácilmente a muchos de los trabajos citados.

3 Además de cumplir su objetivo introductorio, el estudio tiene dos grandes virtudes. Poco se sabía sobre este autor. Sin embargo, gracias a un esfuerzo de exhumación documental que se trasluce a lo largo del texto, Jesús Ponce Cárdenas ha conseguido reconstruir su vida y su entorno, facilitando con ello la comprensión del Compendio. 
Asimismo, la introducción es rica en sugerencias para futuras investigaciones, como por ejemplo el análisis del círculo gongorino del reino de Jaén, donde además del propio Villar destacó, entre otros, el comentarista Salcedo Coronel.

El texto editado, que Ponce Cárdenas moderniza según las normas del proyecto, consta de dos apartados: las proposiciones sexta («En todo género de poesía fue eminente don Luis de Góngora») y séptima ('Don Luis de Góngora fue el mayor poeta de España'). Nada se sabe de las cinco primeras. También se ignora si el Compendio concluía en la séptima. Sin embargo, la obra tiene más enjundia de lo que podrían sugerir su concisión y fragmentariedad. En ocasiones, sus aciertos son evidentes a simple vista. Con frecuencia, la anotación del editor ilumina aspectos que pasarían desapercibidos en una lectura apresurada.

5 Tras una introducción sobre cómo cada género literario merece un estilo distinto, muy influida por la retórica clásica, Villar dedica la proposición sexta a defender que Góngora fue eminente en todos ellos: epigrama, épica, lírica, poesía satírica y burlesca, poesía sacra, y «lo cómico» (es decir, el teatro, único ámbito donde reconoce la primacía de Lope). En su conclusión, Ponce Cárdenas destaca dos aportaciones pioneras: el énfasis en Góngora como poeta epigramático y la categorización de obras como el Polifemo, las Soledades, y el Panegírico en el género heroico. La segunda propuesta constituye una impugnación implícita del Antídoto (c. 1614-1615) de Jáuregui.

Pero no son estos los únicos méritos del texto. Como muestra del interés del Compendio, examinaré brevemente el inicio del apartado sobre los epigramas (páginas 14-16) a modo de complemento al análisis del editor:

... en el genio de las epigramas [...] no le ha igualado alguno en Italia ni en Grecia [...] mas, ¿qué mucho si su desvelo fue llave maestra para manifestar cuantos conceptos y adornos han tenido escondidos y reclusos todas las edades? Engolfose don Luis en el océano abundante y provechoso de la lección antigua y tomando alturas de seguros polos, halló nuevos y no conocidos rumbos, Colón de no menos preciosas Indias [...]

7 Esta cita contiene tres ideas útiles para comprender el encaje de Góngora en el Barroco. En primer lugar, si bien durante el siglo XVII pareció imponerse la idea de que, tras la antigüedad clásica, no volvió a hacerse nada nuevo bajo el sol, tal tesis convivió en tensión con la teoría de la perfectibilidad de la poesía, divulgada en el Renacimiento por Julio César Escalígero. En este sentido, la insistencia en la superioridad de Góngora respecto a los autores grecolatinos es significativa. Se trata de un leitmotiv que el Compendio comparte con el Apologético en favor de Don Luis de Góngora (Lima, 1662) de Espinosa Medrano. El gongorismo alteró la percepción de los clásicos, que ya no se vieron tanto como cimas inalcanzables sino como acicates para la emulación ${ }^{1}$.

En segundo lugar, la definición de Góngora como «llave maestra» de la agudeza y la retórica es perspicaz. Ponce Cárdenas le hace justicia en sus notas. Por un lado, no es casual que Gracián acuda con más frecuencia a él que a ningún otro poeta para ilustrar su taxonomía del conceptismo. Góngora es la cifra del arte del ingenio. Por otro lado, la expresión tiene connotaciones de ocultamiento elitista en consonancia con la atribuida Carta en respuesta, donde Góngora habría sostenido que las Soledades son para quienes puedan «quitar la corteza y descubrir lo misterioso que encubren». En este sentido, Villar aplaude al Góngora maduro que rehuyó «las alabanzas del vulgo» para penetrar «lo más escondido del Parnaso». 
9 En tercer lugar, la comparación con Cristóbal Colón no es un lugar común, sino una analogía casi profética que puede relacionarse con el epíteto de Góngora como 'Homero español', del que también se hace eco el Compendio. Lope criticó la nueva poesía, pues le pareció extremada y no susceptible de crear escuela. El impacto del gongorismo no solo en España, sino también en la América virreinal (sirva, por todos, Sor Juana) desmintió su pronóstico. También robusteció ex post facto la analogía entre Góngora y Homero. No en vano ambos abrieron nuevas sendas para la poesía. Así operó la translatio studii o transmisión del conocimiento, de la Grecia de Homero y la Roma de Virgilio a la España de Góngora, que culminó el movimiento hacia poniente como un nuevo Colón.

Una vez mostrada la superioridad de Góngora en (casi) todos los géneros, la proposición séptima es el corolario del razonamiento anterior: «Don Luis de Góngora fue el mayor poeta de España». Villar nos ofrece un canon de diecinueve autores: Ercilla, Cairasco, Figueroa, Camoens, Herrera, el conde de Salinas, Mira de Amescua, Valdivielso, Ledesma, el conde de Villamediana, Calderón, Bonilla, los hermanos Argensola, Pantaleón de Ribera, Villaizán, Pellicer, Salinas y Hurtado de Mendoza. A su juicio, estos ingenios «son estrellas que felizmente han influido la poesía española», si bien quedan eclipsados ante «los luminares mayores»: Mena en el siglo XV, Garcilaso en el XVI, y Góngora en el XVII, a quien Villar entroniza como el mejor de la terna.

Dejando a un lado la arbitrariedad de este tipo de listados, advertida por Ponce Cárdenas (no figuran ni Lope, ni Quevedo, ni Jáuregui, acaso por ser los principales detractores de la nueva poesía), dos aspectos llaman poderosamente la atención. Por un lado, la grandiosa imagen del firmamento literario, que acoge reminiscencias de la estética conceptista y parece anticipadora de Gracián. Por el otro, el énfasis en Góngora como único ingenio «admitido por dueño y quien a fuerza de estudio rompió la cárcel a la erudición castellana». La infrecuente expresión «romper la cárcel», retomada siglos después por Lezama Lima en Oppiano Licario, confirma la visión de Góngora como experimentador del lenguaje que empujó los límites del decir y del pensar.

En definitiva, no era tarea sencilla divulgar el Compendio, pues es un texto denso y por momentos difícil. No obstante, la obra revela todo su potencial gracias a la clarificadora introducción y esmeradas notas. Además, la página web del Labex Obvil que acoge la edición dispone de una interfaz de manejo sencillo e intuitivo que permite tanto la lectura exhaustiva como la consulta ocasional, en múltiples formatos (libro electrónico epub, html, tei, y txt). Gracias a los hipervínculos que conectan los textos de la polémica gongorina entre sí y con la propia obra poética de Góngora ${ }^{2}$, esta plataforma -de acceso gratuito- permitirá una visión de conjunto de uno de los acervos críticos más emblemáticos de las letras hispánicas. En este marco, y tras la rigurosa edición de Jesús Ponce Cárdenas, Francisco del Villar no podrá ser ignorado en futuros estudios sobre la recepción crítica del gongorismo en el siglo XVII. 


\section{NOTAS}

1. Siguiendo esta senda del comparatismo, Jesús Ponce Cárdenas analiza en detalle esta práctica en su más reciente monografía: La imitación áurea (Cervantes, Quevedo, Góngora) (2016). Héctor Ruiz publicará próximamente el Apologético de Espinosa Medrano dentro del mismo «Proyecto Góngora».

2. Góngora, Luis de. 2016. Poesía, editado por Antonio Carreira (OBVIL) http://obvil.parissorbonne.fr/corpus/gongora/gongora_obra-poetica/

\section{AUTORES}

\section{LUIS CASTELLVÍ LAUKAMP}

Universidad de Cambridge (Christ's College) 